\title{
Study of intramolecular isotope heterogeneity of organic oxy acids in order to detect sophisticated wines and juice drinks
}

\author{
Helen Kuzmina, Lev Oganesyants, Alexander Panasyuk, and Anatoliy Zyakun \\ State scientific institution of All-Russia scientific and research institute of beer brewing, soft drink and wine-making \\ industry (SSI VNIIPB\&VP), 119021 Moscow city, Rossolimo street, house 7, Russian Federation
}

\begin{abstract}
According to International Code of Oenological Practices it is allowed to use acide $\mathrm{L}(+)$ tartrique for wine acidification, while use of synthetic dihydroxysuccinic acid is forbidden. Today it is impossible to differentiate natural dihydroxysuccinic acid from synthetic one by standard techniques. Even by using very sensitive method of isotope mass spectrometry certain difficulties emerge because total isotope characteristics of carbon of dihydroxysuccinic acid of different nature have the same values. However, isotope characteristics of carbon of intramolecular structural groups of dihydroxysuccinic acid made of different raw materials differ significantly. This allows specifying the nature of dihydroxysuccinic acid that is used for making of wines and juice drinks. In Russia, scientific and research institute of beer brewing and wine-making industry carried out a work for studying isotope characteristics of intramolecular isotope heterogeneity of dihydroxysuccinic acid from different origins in order to identify wines and juice drinks. Isotope characteristics of organic oxy acids from different origins were studied including them obtained by synthetic way and numeric range of value $\delta^{13} \mathrm{C}$,\%o were specified. The obtained results allow performing identification tests of wines and juice drinks to find out the products that contain not specified additives as that allowed for its use in production process.
\end{abstract}

\section{Relevance of researches}

According to Code International des Pratiques OEnologiques it is allowed to use acide $\mathrm{L}(+)$ tartrique for wine acidification while it is forbidden to use synthetic dihydroxysuccinic acid.

Today liquid chromatography method and capillary electrophoresis method are used to detect organic acids, including dihydroxysuccinic acid. The disadvantages of the specified methods are low specificity that doesn't allow determining the sources of obtaining of organic acids and estimate authenticity or adulteration of analyzed object. These estimation methods allow us to detect existence of organic acids and measure their concentration. However, it is impossible to determine origin nature of any acid. Even by using very sensitive method of isotope mass spectrometry certain difficulties emerge. Thus, when conducting isotope analysis of dihydroxysuccinic acid obtained from different raw materials, it was found that total isotope characteristics of carbon of dihydroxysuccinic acid of different nature have the same values. In this respect researches aimed to improve methods of estimation of organic acids including establishment of origin appear to be indeed relevant.

\section{Determination of organic oxy acids by using method of isotope mass spectrometry}

\subsection{Method of determination of dihydroxysuccinic acid origin in wines and juice drinks}

In SSI VNIIPB\&VP researches for study of isotope characteristics of dihydroxysuccinic acid obtained from different kinds of raw materials were performed.

For researches dihydroxysuccinic acid was used obtained from different kinds of raw materials: grape, nongrape material of plant origin, synthetic material. Water solutions of pure dihydroxysuccinic acid of different origin were used as control mixtures for verification of all scheme of sample preparation and measurement of isotope characteristics. Dihydroxysuccinic acid in all analyzed samples was precipitated with barium chloride at the certain value of $\mathrm{pH}$, precipitation was rinsed, dried out and divided into three parts. In the first part of precipitation ratio of stable isotopes ${ }^{13} \mathrm{C} /{ }^{12} \mathrm{C}$ was measured to obtain total isotope characteristics of carbon of dihydroxysuccinic acid. The second part of 
Table 1. Isotope characteristics of intramolecular groups of dihydroxysuccinic acid of different origin.

\begin{tabular}{|c|c|c|c|}
\hline \multicolumn{4}{|c|}{ Value $\delta^{13} \mathrm{C}, \%$ } \\
\hline $\begin{array}{c}\text { Name of } \\
\text { sample }\end{array}$ & $\begin{array}{c}\text { Total carbon } \\
\text { of dihydroxy- } \\
\text { succinic acid }\end{array}$ & $\begin{array}{c}\text { Carbon of } \\
\text { carboxyl } \\
\text { group of } \\
\text { dihydroxy- } \\
\text { succinic acid }\end{array}$ & $\begin{array}{c}\text { Carbon of } \\
\text { alkyl group } \\
\text { of } \\
\text { dihydroxy- } \\
\text { succinic } \\
\text { acid }\end{array}$ \\
\hline 1 & 2 & 3 & 4 \\
\hline $\begin{array}{c}\text { Dihydroxy- } \\
\text { succinic } \\
\text { acid } \\
\text { of grape }\end{array}$ & $-21,8 \pm 0.2$ & $-21,2 \pm 0.2$ & $-25,4 \pm 0.2$ \\
\hline $\begin{array}{c}\text { Dihydroxy- } \\
\text { succinic } \\
\text { acid } \\
\text { of corn }\end{array}$ & $-13,6 \pm 0.2$ & $-12,1 \pm 0.2$ & $-14,9 \pm 0.2$ \\
\hline 1 & 2 & 3 & 4 \\
\hline $\begin{array}{c}\text { Synthetic } \\
\text { dihydroxy- } \\
\text { succinic acid }\end{array}$ & $-23,8 \pm 0.2$ & $-25,4 \pm 0.2$ & $-22,2 \pm 0.2$ \\
\hline
\end{tabular}

precipitation was burnt out at the temperature $560{ }^{\circ} \mathrm{C}$ and measurement of isotope characteristics of alkyl group of dihydroxysuccinic acid molecule was performed. In the third part of precipitation carbon of alkyl group was preliminary removed by method of burning-out. Then the third part of precipitation was analyzed by using isotope mass spectrometer to determine isotope characteristics of carboxyl group of dihydroxysuccinic acid molecule. Isotope characteristics of total carbon of dihydroxysuccinic acid salts, carbon of alkyl group and carbon of carboxyl group of dihydroxysuccinic acid molecule are the values of dihydroxysuccinic acid qualification. In Table 1 there are results of research of study of isotope characteristics of intramolecular structural groups of dihydroxysuccinic acid of different origin.

Analysis of obtained data showed that isotope characteristics of dihydroxysuccinic acid of different origin differ significantly. Moreover, distinctive peculiarity of isotope characteristics of structural groups of dihydroxysuccinic acid molecule of plant origin and synthetic dihydroxysuccinic acid was determined. So, fraction of "light" isotope ${ }^{12} \mathrm{C}$ in alkyl group of plant dihydroxysuccinic acid is higher than in carboxyl group, while in synthetic dihydroxysuccinic acid fraction of "light" isotope is higher in carboxyl group.

Grape wines and juice drinks were subject to isotope analysis to measure isotope characteristics of carbon of intramolecular structural groups of dihydroxysuccinic acid in order to determine nature of its origin. In this regard obtained ratios of abundance of stable isotopes ${ }^{13} \mathrm{C}$ and ${ }^{12} \mathrm{C}$ of control mixtures were compared with the results of analyzed wine or juice drink and on the basis of coincidence or variation rate it was judged about origin of dihydroxysuccinic acid in them. Results are specified in Table 2 .
Table 2. Characteristic of isotope content of carbon of dihydroxysuccinic acid in grape wines and juice drinks.

\begin{tabular}{|c|c|c|c|}
\hline \multicolumn{4}{|c|}{ Value $\delta^{13} \mathrm{C}, \% o$} \\
same of \\
sample & $\begin{array}{c}\text { Total } \\
\text { carbon of } \\
\text { dihydroxy- } \\
\text { succinic } \\
\text { acid }\end{array}$ & $\begin{array}{c}\text { Carbon of } \\
\text { carboxyl } \\
\text { group of } \\
\text { dihydroxy- } \\
\text { succinic } \\
\text { acid }\end{array}$ & $\begin{array}{c}\text { Carbon of } \\
\text { alkyl group } \\
\text { of } \\
\text { dihydroxy- } \\
\text { succinic } \\
\text { acid }\end{array}$ \\
\hline $\begin{array}{c}\text { Dry white } \\
\text { grape wine }\end{array}$ & & & \\
Sample 1 & $-22,9 \pm 0.2$ & $-21,1 \pm 0.2$ & $-24,7 \pm 0.2$ \\
Sample 2 & $-16,5 \pm 0.2$ & $-15,1 \pm 0.2$ & $-18,3 \pm 0.2$ \\
Sample 3 & $-21,5 \pm 0.2$ & $-24,3 \pm 0.2$ & $-19,5 \pm 0.2$ \\
Juice drink & & & \\
Sample 1 & $-23,7 \pm 0.2$ & $-22,2 \pm 0.2$ & $-26,0 \pm 0.2$ \\
Sample 2 & $-15,3 \pm 0.2$ & $-13,3 \pm 0.2$ & $-17,1 \pm 0.2$ \\
Sample 3 & $-21,3 \pm 0.2$ & $-24,1 \pm 0.2$ & $-19,7 \pm 0.2$ \\
\hline
\end{tabular}

When analyzing data specified in Table 2 the same principles of difference of isotope characteristics of dihydroxysuccinic acid of different origin were found out. In samples 1 and 2 of wine and juice drink there are dihydroxysuccinic acid of plant origin but from different kinds of raw materials. Sample 3 contains synthetic dihydroxysuccinic acid that is forbidden for use. In the samples of analyzed juice drinks the same tendency is observed.

When conducting researches, dependence of isotope characteristics of dihydroxysuccinic acid from nature of its origin at the level of intramolecular isotope heterogeneity was found. On the basis of obtained results a method of estimation of dihydroxysuccinic acid origin has been developed based on determination of difference in content of ${ }^{13} \mathrm{C}$ isotope in carboxyl and alkyl groups of dihydroxysuccinic acid in relation to their total characteristic. The use of this method will allow to carryout identification tests of wines and juice drinks in order to discover adulterated products.

\subsection{Method of determination of organic oxy acids origin in wines and juice drinks}

According to Code Int ernational des Pratiques OEnologiques, it is allowed to use some organic acids when making wines - dihydroxysuccinic, lactic, malic and citric acids. Moreover, organic oxy acids are also widely used in production of juices and juice drinks. But some dishonest producers use acids that are not allowed for use, in particularly, synthetic one, for production of goods. As said above, currently existed methods don't allow to determine nature of origin of organic acids, so, it is necessary to develop new analytic methods of identification based on detection of nature of ingredients that product contains.

It is known that all plants on Earth differ in type of photosynthesis. Isotope characteristics of carbon of vegetable products are in direct relationship to way of photo assimilation of atmospheric carbon by 
Table 3. The characteristics of the carbon isotopic composition of organic oxy acids of different origins.

\begin{tabular}{|c|c|c|}
\hline \multicolumn{3}{|c|}{ Value $\mathrm{S}^{13} \mathrm{C}\left(\%_{00}\right)$} \\
\hline Name & $\begin{array}{c}\text { The total } \\
\text { carbon } \\
\text { tartaric } \\
\text { acid salts }\end{array}$ & $\begin{array}{c}\text { The total } \\
\text { carbon } \\
\text { organic acid } \\
\text { salts }\end{array}$ \\
\hline $\begin{array}{c}\text { The organic } \\
\text { acids of grape } \\
\text { origin }\end{array}$ & $-21,8 \pm 0.2$ & $-21,9 \pm 0.2$ \\
\hline $\begin{array}{c}\text { The organic } \\
\text { acids of non- } \\
\text { grape origin }\end{array}$ & $-13,6 \pm 0.2$ & $-13,1 \pm 0.2$ \\
\hline
\end{tabular}

plants. Method of ratio measurement of stable isotopes ${ }^{13} \mathrm{C}$ and ${ }^{12} \mathrm{C}$ of organic acids is based on this principle and is intended for discovering of adulterated products.

SSI VNIIPB\&VP carried out the study to determine the origin of organic oxy acids in wine and juice drinks. In the analyzed samples of wine and juice drinks under the certain conditions the salt precipitation of tartaric acid was carried out, the resulted precipitate was collected, and subjected to the isotopic mass-spectrometric analysis with making the relations of stable isotopes ${ }^{13} \mathrm{C} /{ }^{12} \mathrm{C}$ to obtain the total isotopic characteristics of tartaric acid. The remained supernatant was subjected to a specific sample preparation, precipitated the salts of the remained organic acids and the resulted precipitate was analyzed by the isotope mass-spectrometry to obtain the stable carbon isotopes and their relationships.

As the control mixtures, the aqueous solutions of pure organic acids of different origin were used: the organic oxacids from grapes, the organic oxy acids of non-grapes origin.

The research results are shown in Table 3.

The isotopic characteristics of the total carbon tartaric acid salts, and the salts of organic oxy acids are the indicators of the qualification of organic acids and the nature of their origin. As seen in the table, the given quantitative values of the total carbon isotopic characteristics of the salts of tartaric acids and the total carbon salts of organic oxoacids derived from different raw materials, are significantly different.

To develop a method of determining the origin of organic oxy acids 30 samples of wines and 10 samples of juice drinks were analyzed. Table 4 shows the average measurement data of the isotopic characteristics of organic acids in these products.

As seen in the table, the samples of wine and juice drinks vary in the carbon isotopic characteristics of tartaric acid and the carbon of organic oxy acids. When comparing the data in Table 3 and the data in Table 4, it can be stated: the organic acids contained in the analyzed samples of wine and juice drinks, indicated A, are of grape nature.
Table 4. The characteristics of the carbon isotopic composition of organic oxy acids in wine and juice drinks.

\begin{tabular}{|c|c|c|}
\hline \multicolumn{3}{|c|}{ Value $\delta^{13} \mathrm{C}\left({ }^{0} / 00\right)$} \\
\hline Name & $\begin{array}{l}\text { The total carbon } \\
\text { tartaric acid salts } \\
\text { (the average } \\
\text { result) }\end{array}$ & $\begin{array}{c}\text { The total carbon } \\
\text { organic oxy acid } \\
\text { salts (the average } \\
\text { result) }\end{array}$ \\
\hline $\begin{array}{c}\text { Grape wines A } \\
\text { (21 samples ) }\end{array}$ & $-22,1 \pm 0.2$ & $-22,5 \pm 0.2$ \\
\hline $\begin{array}{c}\text { Grape wines B } \\
\text { (9 samples) }\end{array}$ & $-17,3 \pm 0.2$ & $-17,1 \pm 0.2$ \\
\hline $\begin{array}{c}\text { Juice drinks A } \\
\text { (6 samples) }\end{array}$ & $-21,9 \pm 0.2$ & $-22,3 \pm 0.2$ \\
\hline $\begin{array}{c}\text { Juice drinks B } \\
\text { (4 samples) }\end{array}$ & $-17,5 \pm 0.2$ & $-17,7 \pm 0.2$ \\
\hline
\end{tabular}

The samples, indicated B, are prepared with applying the organic acids of non-grape origin.

Based on the research results, the method was developed to determine the origin of organic oxy acids in wine and juice drinks.

\section{Conclusions}

The results of these studies suggest the following conclusions:

- The total carbon isotopic characteristics of tartaric acid of different origin are significantly different;

- The relations of the stable isotopes ${ }^{13} \mathrm{C} /{ }^{12} \mathrm{C}$ of the intramolecular structural groups of tartaric acid vary depending on the method of its preparation;

- When inserting the organic acids of non-grape origin in the grape wine and grape juice drinks, the quantitative isotopic characteristics of the total carbon of the remained organic acids vary significantly.

The new methods of product identification are developed:

- The method of determining the origin of tartaric acid in wine and juice drinks.

- The method of determining the origin of organic oxy acids in wine and juice drinks.

The proposed methods will allow carrying out the identification tests of wines and juice drinks to identify the products containing supplements, which are not regulated for applying in production.

\section{References}

[1] L. Oganesyants, A. Panasyuk, E. Kuzmina, A. Zyakun, Le Bulletin de L'OIV (2012)

[2] L.A. Oganesyants, A.L. Panasyuk, E.I. Kuzmina, A.M. Zyakun, Food process.ind., I (2013)

[3] A.M. Zyakun, L.A. Oganesyants, A.L. Panasyuk, E.I. Kuzmina, A.A. Shilkin, B.P. Baskunov, V.N. Zakharchenko, and V.P. Peshenko, J.Anal.Chem., 68 (2013) 